\title{
AVALIAÇÃO DAS PRÁticas DO SISTEMA DE PRODUÇÃO E SEUS EFEITOS NA ARMAZENAGEM DE BULBOS DE CEBOLA
}

\author{
Lauri João Marconatto ${ }^{1 *}$, Leandro Luiz Marcuzzo ${ }^{1}$ \\ ${ }^{1}$ Instituto Federal Catarinense, Campus Rio do Sul, Rio do Sul, 89163-356, Santa Catarina, Brasil \\ *Autor para correspondência: Lauri João Marconatto; e-mail: lauri.marconatto@ifc.edu.br
}

Recebido: 03/06/2020, Aceito: 15/07/2021, Publicado online: 18/10/2021

\begin{abstract}
Resumo
Parte da cebola produzida no estado de Santa Catarina é armazenada em galpões rústicos sem controle ambiental, que favorecem perdas de peso e de qualidade. O presente estudo tem por objetivo a compreensão das causas das perdas de cebola na armazenagem, sua relação e influência pelo uso de insumos e técnicas aplicadas no cultivo e pré-colheita, bem como de parte da infraestrutura de produção para as duas cultivares. Através da coleta de dados com os produtores e amostras de bulbos de seus cultivos que foram armazenados por 140 dias e avaliadas as perdas, apresentou-se que no Alto Vale do Itajaí a cv. Crioula recebe mais chuvas durante a cura, é colhida com menor taxa de estalo, sendo mais suscetível ao brotamento que a cv. Bola precoce. Lavouras com maior produtividade, maiores estandes e maiores volumes de adubação nitrogenada em cobertura, reduzem o brotamento na armazenagem. A desidratação tem menor em relação a produtividade, produção e período de cura, além disso,foi maior em relação tempo que o produtor cultiva cebola. $\mathrm{O}$ apodrecimento é menor com o aumento da produtividade, produção e adubação potássica em cobertura. Nas maiores lavouras existe desperdício de adubos nitrogenados e potássicos que aumentam o custo de produção.
\end{abstract}

Palavras-chave: Allium cepa L., danos, perdas, pós colheita, estocagem.

\section{EVALUATION OF PRODUCTION SYSTEM PRACTICES AND THEIR EFFECTS ON STORAGE OF ONION BULBS}

\begin{abstract}
Production onion part in the Santa Catarina state, Brazil is stored in rustic warehouses without environmental control, which favors losses weight and quality. The purpose of this study is to understand the causes of onion losses in storage, their relationship, and influence using inputs and techniques applied in cultivation and preharvest, as well as part of the production infrastructure for the two cultivars. Through the data collection with the producers and samples of bulbs of their harvest that were stored for 140 days and is evaluated the losses, was presented that in the Alto Vale do Itajaí the cv. Crioula receives more rain during the cure, is harvested with a lower fallen leaves rate, being more susceptible to budding than cv. Bola Precoce. Bulbs originating from crops with higher productivity, a greater number of plants per area, and a higher volume of nitrogen fertilization in coverage, reduce sprouting in storage. Dehydration was lower in relation to productivity, production, curing period, furthermore, experience time of farmer in onion cultivation. To rotting is lower with increased productivity, production, and potassium fertilization during cultivation. There is a waste in nitrogenous and potassic fertilizers that increase the cost of production in crops with the greater planted area.
\end{abstract}

Keywords: Allium cepa L, damage, losses, post-harvest, storage. 


\section{Introdução}

As práticas e insumos aplicados ao cultivo da cebola são reconhecidamente importantes e largamente estudados com vistas a sua produção e produtividade. Entretanto, pouco se encontra em referência a essas práticas com a capacidade de armazenagem do bulbo. Por certo, as práticas culturais aplicadas no cultivo, tais como adubações química e orgânica, calagem, sistema de cultivo, irrigação, espaçamento, ponto de colheita, cura, entre outros e a cultivar, também podem influenciar no comportamento dos bulbos durante a armazenagem. A armazenagem deve proporcionar condições adequadas de teor de umidade e temperatura, para que o produto seja estocado pelo maior tempo possível, sem perda significativa de atributos de qualidade, tais como: apresentação, textura, cor, sabor, aroma e valor nutricional.

$\mathrm{Na}$ região do Alto Vale do Itajaí, é comum que o produtor realize a aplicação de nitrogênio, fosforo e potássio (NPK) em quantidades acima do que é recomendado pelas análises de solo (CQFS, 2004), essa aplicação desequilibrada pode causar discrepâncias nutricionais. Entretanto, é inexistente pesquisas nesta região que avalie $\mathrm{o}$ efeito dessas técnicas na produtividade, qualidade e conservação dos bulbos de cebola (Kutz \& Ernani, 2010).

Em relação aos micronutrientes, Nylund (1952) avaliou o efeito da adição de $\mathrm{B}, \mathrm{Cu}, \mathrm{Fe}$ e $\mathrm{Zn}$ ao solo, e de $\mathrm{Mn}$ via solo com $\mathrm{MnSO}_{4}$, num solo com pH 6,9, nos EUA. Somente o Mn aumentou a produtividade, sendo a maior com 37,5 kg ha-1 de $\mathrm{Mn}$, ou 7,5 kg ha-1 de Mn via foliar, divididos em três pulverizações foliares. Em Santa Catarina, onde ocorrem sintomas de deficiência de $\mathrm{Mn}$, o pH do solo geralmente é maior do que 6,0, onde há predomínio de monocultivo, o teor de matéria orgânica é baixo, os solos são intensivamente cultivados e degradados (Werner et al., 1996).

A densidade de plantio também definida com o estande influencia no tamanho médio final dos bulbos, de forma que quanto maior for o estande mais próximas estarão as plantas entre si e menor será o tamanho médio dos bulbos. Por outro lado, a produtividade aumenta com um maior número de plantas por área, entretanto existe um limite de tamanho mínimo dos bulbos para que tenha valor de comercialização (Baier et al., 2009).

A maturidade fisiológica das plantas na colheita, o método de cura, e as condições meteorológicas predominantes durante o cultivo e cura afetam a aparência e mantém a qualidade dos bulbos de cebola colhidos (Boeing, 2002; Moretti, 2007). O momento da colheita é determinante para a qualidade e estabilidade da cebola durante a armazenagem, além disso, esse momento é definido pelos produtores de acordo com o ponto de estalo. O ponto ou taxa de estalo é caracterizada pela proporção de folhas que tombam pela murcha do pseudocaule, que identifica o momento de maturação fisiológica dos bulbos. É recomendado proceder o arranquio quando o estalo estiver $50-80 \%$, melhor quanto maior esta proporção (Botrel et al., 2015).

Em Santa Catarina a cebola normalmente é colhida durante a segunda quinzena de outubro até o final de dezembro, já a cebola a ser armazenada é colhida no final de novembro e dezembro (EPAGRI, 2013). Durante a armazenagem, o bulbo da cebola sofre influências de condições externas, como temperatura, umidade do ar, composição gasosa da atmosfera, entre outros fatores. A capacidade de conservação dos bulbos depende do manejo e dos tratos culturais da lavoura, das condições climáticas durante a colheita, da cura e do manejo na pós-colheita (Menezes Júnior et al., 2013; Menezes Júnior et al., 2013; Boeing, 2002).

Essa pesquisa teve como objetivo identificar relações entre as perdas por desidratação, apodrecimento e brotação durante a armazenagem com as práticas de cultivo agrícola adotadas pelos produtores, entre elas a adubação, calagem, espaçamento, colheita e cura, e a infraestrutura da propriedade.

\section{Material e Métodos}

O estudo foi realizado armazenando por 140 dias, bulbos de cebola com diâmetros entre 51 e $90 \mathrm{~mm}$ (classe 3 e 4) das cultivares 'Epagri 362' (Crioula) e 'Empasc 352' (Bola Precoce), coletados em diferentes propriedades nos municípios de Alfredo Wagner, Chapadão do Lageado, Imbuia, Ituporanga, Leoberto Leal e Vidal Ramos, todos localizados na região do Alto Vale do Itajaí, no estado de Santa Catarina - Brasil, durante a primeira quinzena de 2014 (safra 1) e repetido na primeira quinzena de 2015 (safra 2).

$\mathrm{Na}$ safra 1 foram coletadas amostras e informações do sistema de produção de 31 produtores. Sendo vinte produtores da cv. Bola Precoce e outros onze da cv. Crioula. Para a safra 2 foram vinte produtores da cv. Bola Precoce e nove da cv. Crioula. Dois dos produtores da cv. Crioula na safra 1, não mais plantaram a mesma cultivar na safra 2. Desta forma foram obtidas 60 repetições entre as duas safras.

As amostras de bulbos visivelmente livres de infecções e injúrias foram coletadas aleatoriamente, em três seções do armazém, onde estavam armazenadas a granel ou em bins, a uma profundidade de até $20 \mathrm{~cm}$. Nas propriedades onde os bulbos estavam armazenados em sacos foram coletadas aleatoriamente três sacos, em 
seções diferentes divididas proporcionalmente ao total da área armazenada, de cada saco foi coletada uma amostra. As amostras de cada seção foram compostas de dezoito bulbos (nove de cada classe 3 e 4), totalizando54 para cada produtor. A quantidade armazenada estimou-se entre 20 a 400 toneladas.

As amostras foram armazenadas individualmente dentro de caixas plásticas vasadas em ambiente com ventilação natural, por 140 dias (Menezes Júnior, 2016). A armazenagem foi feita no armazém da Estação Experimental da Epagri de Ituporanga - SC, localizado

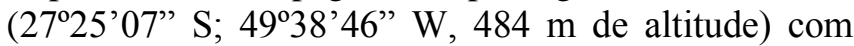
médias internas ao armazém para o período de armazenagem de 27 de janeiro a 16 de junho nos anos de 2014 e 2015. As médias internas ao armazém de temperaturas $\left(19,8^{\circ} \mathrm{C}\right.$ e $\left.19,5^{\circ} \mathrm{C}\right)$ e umidade relativa do ar $(82,6 \%$ e $88,9 \%)$ respectivamente para safras 1 e 2 .

A cada 28 dias os bulbos foram avaliados quanto às perdas parciais de massa fresca (desidratação), apodrecimento e por brotação, sendo que, os bulbos podres e brotados, quando identificados, foram pesados e excluídos. A cada avaliação foram obtidas as porcentagens médias das perdas por amostra e acumuladas a cada período até o final. A soma das perdas acumuladas por amostra para a desidratação, apodrecimento e brotação, foi denominada como perda "Final" e a soma das três perdas "Final" denominada como perda "Total". O cálculo da porcentagem tomou sempre por base o peso da amostra no início do período de armazenagem.

A partir dos dados coletados foram obtidas as 36 variáveis a seguir: Cultivares (CV) Bola Precoce (1) Crioula (2); Safra (SAF) ano 2014 (1) e no ano de 2015 safra (2); Tempo que planta cebola (TP) (anos); Número de pessoas que trabalham no cultivo (NPC); Número de familiares que atuam no cultivo (PFC); Técnico Agrícola na família $(\mathrm{FTF})(\operatorname{sim}=1$, não=2); Média de área plantada (MAP) (ha); Produtividade média por área $\left(\mathrm{t} \mathrm{ha}^{-1}\right)(\mathrm{PMH}) ; \mathrm{A}$ cebola é principal atividade econômica (MD) $($ sim=1, não=2); (VCA) Volume calcário anual ( $\left.\mathrm{tha}^{-1}\right)$ (VCA); Origem do calcário (OTC) (Botuverá (1) Curitiba dolomita (2) e Filler (3); Sistema de cultivo (SC) (transplantio (1), cultivo mínimo (2) e semeadura em plantio direto (3)); Tipo de cobertura verde (TCV) (milho/sorgo (1), alternado (2) e leguminosa (3)); Adubação de plantio ( $\left.\mathrm{kg} \mathrm{ha}^{-1}\right) \mathrm{com}$ : Nitrogênio (NP); Fósforo (PP); Potássio (KP); Adubação em Cobertura $\left(\mathrm{kg} \mathrm{ha}^{-1}\right)$ com: Nitrogênio (NC); Potássio (KC); Micronutrientes (MC) (não (1) e sim (2); Adubação orgânica (AOA) $\left(\mathrm{t} \mathrm{ha}^{-1}\right)$; Número de plantas por área (plantas $\mathrm{m}^{-2}$ ) (PPA); Realizou tombamento dos talos (TSN) (sim (1) e não (2)); Ponto de estalo na colheita (proporção tombadas \%) (EST); Local da cura (OLC) (lavoura (1) e galpão (2)); Dias de cura ( $\mathrm{n}^{\mathrm{o}}$ Dias) (DC); Chuvas durante a cura ( $\mathrm{n}^{\mathrm{o}}$ chuvas)
(CVC); Irrigação da lavoura (IRR) (só sementeira (1), parte da lavoura (2), toda a lavoura (3)); Ocorrência de ervas daninhas (ED) (pouca (1), média (2), muita (3)); Forma de transporte para o galpão (EmT) (ensacada ou granel (1), caixas (2), bins (3)); Ocorrência de doenças durante o cultivo (DSN) (sim (1) não (2)); Expectativa de perdas na armazenagem (EXP) (menor 10\% (1) de 10 a $15 \%$ (2) e maior $15 \%$ (3)); Volume de cebola produzida (número em toneladas) (PRO); Perdas (em $\%)$ : Perda Total (PeT); Perda por Desidratação (PeD); Perda por Podridão $(\mathrm{PeP})$ e Perda por Brotação $(\mathrm{PeB})$.

Os resultados obtidos foram submetidos à análise de Correlação linear de Pearson. As correlações obtidas entre as variáveis foram comparadas pelo teste de " $\mathrm{t}$ " ao nível de $1 \%$ de probabilidade. Os coeficientes de correlação foram considerados qualitativamente como correlação fraca para valores modulados entre 0,00 e 0,30 , correlação moderada para valores de 0,30 até menores que 0,60 , para valores de 0,60 até menores que 0,90 como forte correlação e de 0,90 até menor que 1,00 correlação linear muito forte (Callegari-Jacques, 2003). Foi utilizado o programa estatístico SPSS $^{{ }_{-}}$ $\mathrm{IBM}^{\circledR}$ Statistics para o cálculo e testes estatísticos.

\section{Resultados e Discussão}

Na tabela 1 referente aos resultados da análise da Correlação de Pearson está apresentado apenas os valores de correlação superiores a 0,15 os demais foram eliminados para evitar poluição em demasia a tabela. Da mesma forma para as variáveis que não apresentaram nenhuma correlação significativa, foram eliminadas tanto na linha como na coluna (Tabela 1). Desta forma, variáveis não encontradas nas linhas, serão encontradas nas colunas.

Os resultados da análise para as adubações de plantio apresentaram correlações significativas fortes entre elas, e moderada com a adubação em cobertura com $\mathrm{N}$, e fraca com a adubação com $\mathrm{K}$ em cobertura, sendo todas positivas, no entanto, somente o $\mathrm{P}$ apresentou correlação fraca $(0,23)$ significativa $(5 \%)$ com a produtividade. Por outro lado, $\mathrm{N}$ e $\mathrm{K}$ apresentaram correlação positiva fraca $(0,27)$ e moderada $(0,34)$ respectivamente, com a produção, bem como com a média de área plantada fraca positiva $(0,26)$ para o $\mathrm{N}$ e moderada $(0,39)$ e positiva para $\mathrm{K}$ (Tabela 1). Para as duas safras a médiade fertilizantes aplicados por hectare no plantio foi de $41 \mathrm{~kg}$ de N, $161 \mathrm{~kg} \mathrm{de} \mathrm{P}_{2} \mathrm{O}_{5}$ e $68 \mathrm{~kg}$ de $\mathrm{K}_{2} \mathrm{O}$, em cobertura de $168 \mathrm{~kg}$ de N e $32 \mathrm{~kg}$ de $\mathrm{K}_{2} \mathrm{O}$.Isso indica que produtores com maiores áreas plantadas desperdiçam fertilizante, com destaque ao $\mathrm{N}$, demonstrando que o produtor de cebola aumenta ou diminui o volume de aplicação dos fertilizantes de acordo com recomendações de setores comerciais ligados à indústria de fertilizantes na expectativa de 
aumentar sua produtividade, mas que somente eleva o custo de produção (Marconatto \& Marcuzzo, 2020). Estão adubando excessivamente, tanto no solo como nas pulverizações foliares, provocando inclusive desequilíbrios nutricionais (Kurtz \& Ernani, 2010).

Observou-se ainda uma correlação significativa (1\%) moderada e negativa entre safra e produtividade (0,33 ), apresentando menor produtividades na safra 2 , apesar do aumento na quantidade da aplicação de adubos N-K no plantio da safra $2(0,20 ; 0,22)$. Ocorreram quebras de produção devido a ocorrência de muita chuva no período de desenvolvimento da cultura, da mesma forma, com correlação moderada e negativa $(-0,33)$, a cebola passou a representar a principal atividade econômica em menor número de propriedades (Tabela 1), pela frustação da safra 2 mais produtores diversificaram a produção, para melhorar suas receitas. Para a variável monocultivo o valor de classificação (1) e cultivo diversificado (2). Também apresentou uma redução $(-0,64)$ no volume de calcário aplicado (Tabela $1)$.

O volume de adubo NPK aplicado no plantio tem correlação positiva $(0,22 ; 0,28,0,31)$ respectivamente, com o sistema de cultivo, onde no sistema de plantio direto são utilizados maiores volumes de adubos e no sistema de cultivo com plantio direto foi onde ocorreram maiores $(0,22)$ incidência de doenças (Tabela 1). Pois a produtividade e a conservação de cebola são afetadas pela adubação nitrogenada conforme sistema de plantio (Menezes Júnior et al., 2014; Kurtz et al., 2013; Souza et al., 2013).

Quanto às perdas de peso por brotamento, desidratação e apodrecimento, a correlação foi significativa (1\%), moderada e positiva, fato previsível uma vez que todas crescem com o passar do tempo. Ao analisar a correlação entre as perdas de peso por desidratação, por apodrecimento e brotamento com a perda total observamos que todas são positivas $(0,55$; $0,83 ; 0,75)$ moderada ou altas (Tabela 1$)$ e que a desidratação é a menos significativa, o apodrecimento é a mais significativa das perdas para um período de armazenagem de 140 dias.

Quanto ao brotamento de bulbos, os resultados indicam correlação moderada e significativa (1\%) entre perdas por brotamento e cultivar $(0,48)$. A cv. Crioula apresentou maior brotamento nas duas safras, além da característica da própria cultivar, também influenciada pelo volume de chuvas recebido durante a cura que apresentou correlação moderada e positiva $(0,34)$ demonstrando também que quanto maior o número de chuvas durante a cura maior é o brotamento na armazenagem (Tabela 1).

Houve correlação negativa fraca $(-0,26)$ mas significativa $(5 \%)$ com a proporção do estalo no momento da colheita e o brotamento, demonstrando que quanto maior a proporção do estalo menor a taxa de brotadas na armazenagem. Apresentou também correlação moderada e negativa $(-0,40)$ entre a cultivar e a taxa de estalo, sendo menor para a cv. Crioula onde o brotamento também se apresentou maior (Tabela 1), isso pode ter uma relação direta com o produtor da cv. Crioula que parece não esperar o tempo adequado de estalo para a colheita, que em média é realizada com $54 \%$ de estalo enquanto que o produtor da bola precoce colhe com taxa de estalo médio de $80 \%$, talvez buscando se antecipar em relação ao período chuvoso do final de ano e primeira quinzena de janeiro. Quanto menor a taxa de estalo no momento da colheita maior a brotação durante a armazenagem. Colheitas realizadas antes do momento ideal, alto conteúdo de umidade na folhagem e no "pescoço", maior largura do "pescoço" e presença de substâncias reguladoras de crescimento podem estimular a brotação após a colheita (Lima \& Resende, 2007). A cebola Crioula também apresentou maior brotamento entre outras cultivares como a Pira Ouro, Baia Periforme, Granex 33, Jubileu e Texas Grano 502 (Chagas, 2004).

A correlação da proporção de estalo, produtividade e estande ser negativa ao brotamento estão de acordo com os resultados apresentados por Resende \& Costa (2004) e Resende et al. (2005) onde os espaçamentos maiores entre plantas registram a maior porcentagem de perda de peso de bulbos

A brotação apresentou também correlação moderada, mas negativa $(-0,30)$ com a produtividade e apresentou correlação negativa e fraca $(-0,21)$ com a adubação em cobertura com nitrogênio, que apesar de não ter correlação com produtividade, parece reduzir a brotação na armazenagem. Por outro lado, o aumento do número de plantas por área apresentou correlação negativa fraca $(-0,26)$ mas significativa $(5 \%)$ com o brotamento. Com o aumento do estande, os bulbos produzidos normalmente são menores, mas por serem em maior número a tendência é aumentar a produtividade (Menezes Júnior \& Vieira Neto, 2012), conforme correlação positiva moderada $(0,34)$ apresentada entre o estande e produtividade (Tabela 1), indicando que o aumento da produção por área diminui a brotação durante a armazenagem, desta forma existe ainda um indicativo que bulbos menores tendem a germinar menos. Não houve correlação significativa entre brotação e produção. Os produtores com mais experiência não se correlacionam com produtividade, no entanto, correlaciona-se positiva e fracamente $(0,23)$ com a média de área plantada (Tabela 1), demonstrando serem os mais experientes os detentores de maior área plantada. 
Tabela 1. Correlação entre safras, cultivares, conjuntura da propriedade, fatores, técnicas e insumos de produção e perdas na armazenagem. Epagri/Ituporanga, 2015.

\begin{tabular}{|c|c|c|c|c|c|c|c|c|c|c|c|c|c|c|c|c|c|c|c|c|c|c|c|c|c|c|c|c|}
\hline ROT & SAF & PFC & FTF & MAP & $\mathrm{PMH}$ & $\mathrm{MD}$ & OTC & SC & NP & PP & KP & NC & KC & MC & $A O A$ & PPA & TSN & EST & OLC & $D C$ & CVC & IRR & EXP & PRO & PeT & PeD & PeP & PeB \\
\hline CV & & & & 0.18 & & & & & & & & & & & & & $-0,40^{* *}$ & ${ }^{*}-0,40^{* *}$ & & & $0,49^{* *}$ & & & & $0,22^{*}$ & & & $0,48^{* *}$ \\
\hline TP & & -0.17 & $-0,31^{* *}$ & ${ }^{* *} 0,23^{*}$ & & & $0,21^{*}$ & & 0.19 & & 0.18 & & & & $0,38^{* *}$ & -0.2 & & & & $-0,24^{*}$ & & -0.2 & & & & $0,26^{*}$ & $0,25^{*}$ & -0.18 \\
\hline NPC & & $0,42^{* *}$ & $0,25^{*}$ & ${ }^{*} 0,48^{* *}$ & 0.21 & 0.18 & & & & & & 0.2 & $0,22^{*}$ & & & $0,30^{* *}$ & & 0.17 & $0,22^{*}$ & & & $0,48^{* *}$ & & $0,60^{* *}$ & & & & \\
\hline PFC & $-0,37^{* *}$ & 1 & & & & $0,32^{* *}$ & $-0,35^{* *}$ & & & & & & & & & & & & & & & & & $0,35^{* *}$ & & & & $0,22^{*}$ \\
\hline MAP & & 0.17 & & 1 & & & & & & & & $0,26^{*}$ & & & & & & & & & 0.2 & & & $0,73^{* *}$ & & & & \\
\hline PMH & $-0,33^{* *}$ & 0.16 & & & 1 & $0,23^{*}$ & & & & $0,23^{*}$ & & & & 0.17 & & $0,34^{* *}$ & & & & & & $0,26^{*}$ & & $0,42^{* *}$ & $-0,46^{* *}$ & -0.2 & $-0,42^{* *}$ & $-0,30^{* *}$ \\
\hline $\mathrm{MD}$ & $-0,33^{* *}$ & $0,32^{* *}$ & & & $0,23^{*}$ & 1 & & & & & & $0,35^{* *}$ & & & & & & & & & & & & 0.15 & & & & -0.16 \\
\hline VCA & $-0,64^{* *}$ & $0,38^{* *}$ & -0.2 & $-0,26^{*}$ & 0.19 & $0,37^{* *}$ & $-0,72^{* *}$ & & & & & & & & & & & & & & & & & & & & & \\
\hline OTC & $0,62^{* *}$ & $-0,35^{* *}$ & & 0.15 & -0.17 & -0.2 & 1 & & 0.21 & & $0,23^{*}$ & & & & & & & & & & & & & & & & & \\
\hline TCV & & & & & & & & & & & & & & $-0,33^{* *}$ & 0.17 & $0,23^{*}$ & & 0.17 & & & & & & & & & & \\
\hline $\mathrm{NP}$ & 0.2 & & & & & & 0.21 & $0,22^{*}$ & 1 & $0,63^{* *}$ & * $0,89^{* *}$ & ${ }^{*} 0,89^{* *}$ & & 0.18 & & & & & & & & & & & & & & \\
\hline PP & & & $0,25^{*}$ & & $0,23^{*}$ & & & $0,28^{*}$ & $0,63^{* *}$ & 1 & $0,69^{* *}$ & ${ }^{*} 0,43^{* *}$ & & 0.17 & & & & & & & $0,22^{*}$ & $0,31^{* *}$ & & 0.2 & & & & \\
\hline $\mathrm{KP}$ & $0,22^{*}$ & & 0.19 & & & & $0,23^{*}$ & $0,31^{* *}$ & $0,89^{* *}$ & $0,69^{* *}$ & 1 & $0,38^{* *}$ & & 0.2 & & & & & & & & & & 0.17 & & & & \\
\hline $\mathrm{NC}$ & & & & $0,26^{*}$ & & $0,35^{* *}$ & & & $0,89^{* *}$ & $0,43^{* *}$ & $0,38^{* *}$ & 1 & $0,22^{*}$ & & & & & & & & & & & $0,27^{*}$ & & & & -0.21 \\
\hline KC & & -0.15 & & $0,39^{* *}$ & & & & & & & & $0,22^{*}$ & 1 & & & & & & & & & & & $0,34^{* *}$ & & & $-0,22^{*}$ & \\
\hline$A O A$ & & & & & & & & -0.2 & & -0.2 & & & & $-0,27^{*}$ & 1 & & & & & & $-0,25^{*}$ & & & & & & & \\
\hline PPA & & 0.21 & 0.19 & 0.18 & $0,34^{* *}$ & & & $0,36^{* *}$ & & & & 0.17 & & & & 1 & & 0.16 & & & -0.15 & & & $0,25^{*}$ & $-0,29^{*}$ & & & $-0,26^{*}$ \\
\hline TSN & & & & 0.2 & & & & & & & & & & $0,37^{* *}$ & & 0.19 & 1 & $0,63^{* *}$ & & & -0.16 & & & $0,23^{*}$ & & & & \\
\hline EST & & & & 0.16 & & & & & & & & & & 0.19 & & 0.16 & $0,63^{* *}$ & 1 & & & $-0,32^{* *} c$ & $0,36^{* *}$ & & & & & & $-0,26^{*}$ \\
\hline DC & & & & & & & & 0.16 & & & & & & $-0,25^{*}$ & & & & -0.16 & $-0,58^{* *}$ & 1 & $0,52^{* *}$ & & & & & & & 0.17 \\
\hline IRR & & 0.19 & & & $0,26^{*}$ & $0,22^{*}$ & & & & $0,31^{* *}$ & & 0.17 & & & & 0.2 & & $0,36^{* *}$ & & & & 1 & & $0,35^{* *}$ & & & & \\
\hline ED & & & $0,30^{*}$ & 0.21 & & & 0.19 & 0.17 & & & & & 0.21 & & & & & & $-0,31^{* *}$ & 0.15 & & & & & & & & $0,24^{*}$ \\
\hline EmT & & 0.19 & & & $0,25^{*}$ & & & & & & $-0,24^{*}$ & * $\quad-0.2$ & & $0,24^{*}$ & $-0,35^{* *}$ & $0,23^{*}$ & & & & & & -0.2 & & & & & & \\
\hline DSN & & & & & & & $-0,26^{*}$ & $0,22^{*}$ & & & & & & & & 0.19 & & & & & & & & & & & & \\
\hline РeT & & & & & $-0,46^{* *}$ & -0.2 & & & & & & -0.2 & & & & $-0,29^{*}$ & & & & & & & $0,25^{*}$ & $-0,36^{* *}$ & 1 & $0,55^{* *}$ & $0,83^{* *}$ & $0,75^{* *}$ \\
\hline PeD & & -0.19 & & & -0.21 & & & & & & & & & & & & 0.15 & & -0.16 & & & & & $-0,29^{*}$ & $0,55^{* *}$ & 1 & $0,41^{* *}$ & $0,27^{*}$ \\
\hline PeP & & & & -0.2 & $-0,42^{* *}$ & & & & & & & & $-0,22^{*}$ & & 0.18 & -0.2 & & & & & & -0.1 & $0,24^{*}$ & $-0,40^{* *}$ & $0,83^{* *}$ & $0,41^{* *}$ & 1 & $0,26^{*}$ \\
\hline
\end{tabular}

**A correlação é significativa no nível 0,01 ; *A correlação é significativa no nível 0,05 . 
Abreviações da tabela 1: Cultivar (CV); Safra (SAF); Tempo que planta cebola (TP); Pessoas que trabalham no cultivo (NPC); Familiares que atuam no cultivo (PFC); Técnico Agrícola na família (FTF); Média de área plantada (MAP); Produtividade média por área $(\mathrm{PMH}) ; \mathrm{A}$ cebola é principal atividade econômica (MD); Volume calcário anual (VCA); Origem do calcário (OTC); Sistema de cultivo (SC); Tipo de cobertura verde (TCV); Adubação de plantio com: Nitrogênio (NP); Fósforo (PP); Potássio (KP); Adubação em Cobertura com: Nitrogênio (NC); Potássio (KC); Micronutrientes (MC); Adubação orgânica (AOA); Número de plantas por área (PPA); Realizou tombamento artificial dos talos (TSN); Ponto de estalo na colheita (EST); Local da cura (OLC); Dias de cura (DC); Chuvas durante a cura (CVC); Irrigação da lavoura (IRR); Ocorrência de ervas daninhas (ED); Forma de transporte para o galpão (EmT); Ocorrência de Doenças (DSN); Expectativa de perdas na armazenagem (EXP); Volume de cebola produzida (PRO); Perdas: Tota (PeT)1; Desidratação (PeD); Podridão (PeP)e Brotadas (PeB).

A perda por desidratação não foi influenciada por nenhum dos fatores analisados a nível de significância $(1 \%)$, apenas correlacionou-se significativamente $(5 \%)$ de forma positiva fraca $(0,26)$ com o tempo que o produtor cultiva a cebola e negativa fraca com a produção $(-0,29)$ e também negativa e fraca $(-0,21)$ com a produtividade. Isso demonstra que não obrigatoriamente a experiência com o cultivo levou a adoção de práticas que reduzam as perdas por desidratação. Isso pode ser explicado pelo fato de que produtores que plantam a mais tempo realizam a cura em períodos mais curtos conforme demonstrou ser significativa $(5 \%)$ a correlação negativa fraca $(-0,24)$ entre eles (Tabela 1), menor período de cura leva os bulbos com maior teor de umidade para o armazém e a mesma acaba sendo evaporada durante a armazenagem produzindo maiores perdas por desidratação (MARCONATTO \& MARCUZZO, 2021). Também indica que os produtores com mais tempo de experiência em cultivo de cebola não são os detentores de melhores produtividade, nem de produção.

As perdas por apodrecimento têm correlação significativa (1\%) moderada e negativa com a produtividade $(-0,42)$ e volume de produção $(-0,40)$ e fraca, porém significativa $(5 \%)$ com a quantidade de potássio $(-0,22)$ aplicada em cobertura. Por outro lado, apresentou-se correlação positiva fraca para tempo que o produtor cultiva cebola $(0,25)$ e expectativa de perdas na armazenagem $(0,24)$ pelo produtor (Tabela 1). Semelhante a condição anterior os produtores que obtém melhores produtividade e produção também produzem bulbos com maior resistência ao apodrecimento e ainda tem maior consciência da ocorrência das perdas na armazenagem e parecem adotarem melhor as recomendações técnicas, esses não são os produtores mais experientes no cultivo da cebola e varia conforme as condições climáticas de cada safra (Marconatto et al., 2017).

Com exceção ao potássio em cobertura, as adubações não apresentaram correlações significativas com as outras perdas. $\mathrm{O} \mathrm{K}$ em cobertura que apresentou correlação significativa $(5 \%)$ negativa fraca $(-0,22)$ para o apodrecimento é o nutriente que tem grande importância juntamente com o nitrogênio para plantas que armazenam reservas em estruturas especializadas como um bulbo (Loué, 1978). O K também se caracteriza por ser um ativador de grupos de enzimas vegetais, que controlam as reações que ocorrem na célula, principalmente das sintetases, desidrogenases, oxiredutases, quinases e transferases, estando estreitamente relacionado com os processos de formação de compostos nitrogenados como aminoácidos e proteínas, e na síntese, translocação e armazenamento de açúcares (Malavolta, 1980; Malavolta \& Crocomo, 1982; Chaves \& Pereira, 1985). A melhoria na síntese de compostos simples (monossacarídeos e aminoácidos) em compostos mais complexos como amidos e proteínas, aumentam a resistência ao ataque microbiológico e consequente o apodrecimento. $\mathrm{O}$ resultado corrobora com trabalho de Resende \& Costa (2008) que também apresentaram redução linear nas perdas com o incremento das doses de K, mas contraria Resende \& Costa (2009) que apresentou mínima perda com ausência de adubação potássica.

\section{Considerações finais}

Os produtores de cebola com maiores áreas plantadas na região do Alto Vale do Itajaí estão desperdiçando adubos nitrogenados e potássicos e aumentando seus custos de produção sem aumentar a produtividade, mas foi constatado que a aplicação do potássio é uma prática importante, quando aplicado em cobertura, pois promove o aumento de produtividade e consequente maior produção, com redução das perdas na armazenagem

A cebola cv. Crioula é mais suscetível ao brotamento que a cv. Bola precoce, porque recebem mais chuvas durante a cura e por serem colhidas com menor taxa de estalo, enquanto que os bulbos obtidos de lavouras com maior produtividade, maiores estandes e maiores volumes de adubação nitrogenada em cobertura, apresentaram menores perdas por brotamento.

As perdas por desidratação são pouco influenciadas pelas práticas de cultivo, mas se apresentam maiores em 
relação ao tempo que o produtor cultiva cebola, e menores em relação a maior produtividade, maior produção e maior período de cura e as perdas por apodrecimento são menores com o aumento da produtividade e produção, bem como com o aumento de adubação potássica em cobertura.

\section{Referências}

Baier, J. E.; Resende, J. T.; Galvão, A. G.; Battistelli, G. M.; Machado, M. M.; Faria, M. V. Produtividade e rendimento comercial de bulbos de cebola em função da densidade de cultivo. (2009). Ciências Agrotécnicas, 33:(2), 496-501.

Boeing, G. Fatores que afetam a qualidade da cebola na agricultura familiar catarinense. (2002). Instituto Cepa/SC.

Botrel, N. Maldonade, I. R.; Oliveira, V. R. (2015) Colheita, comercialização e pós-colheita. In: Souza, R. J.; Assis, R. P.; ARAÚJO, J.C. (Orgs.). Cultura da Cebola. (339-370). Lavras: Ed. UFLA

Callegari-Jacques, S. M. (2003) Bioestatística: princípios e aplicações. Artmed, Porto Alegre.

Chagas, S. J. R.; Resende, G. M.; Pereira, L. V. Características qualitativas de cultivares de cebola no sul de Minas Gerais. (2004). Ciências Agrotécnicas, 28:(1), 102-106.

Chaves, L. H. G.; Pereira, H. H. G. (1985). Nutrição e adubação de tubérculos. Campinas: Fundação Cargill. Comissão de Química e Fertilidade do Solo - RS/SC (CQFS). (2004). Manual de adubação e de calagem para os Estados do Rio Grande do Sul e de Santa Catarina. Porto Alegre: SBCS-NRS/EMBRAPA-CNPT.

EPAGRI - Empresa de Pesquisa Agropecuária e Extensão Rural de Santa Catarina (2013). Sistema de produção para a cebola - Santa Catarina. Florianópolis: Epagri.

Kurtz, C.; Ernani, P. R.; Pauletti, V.; Menezes Junior, F.O.G.; Vieira Neto, J. Produtividade e conservação de cebola afetadas pela adubação nitrogenada no sistema de plantio direto. (2013). Horticultura Brasileira, $31:(4), 559-567$

Kurtz, C.; Ernani, P. R. Produtividade de cebola influenciada pela aplicação de micronutrientes. (2010). Revista Brasileira de Ciências do Solo, 34:(1), 133-142.
Lima, M. A. C.; Resende, G. M. (2007). Cultivo da cebola no Nordeste: Colheita e pós-colheita. Embrapa Semi-Árido. Sistemas de Produção, 3. Versão Eletrônica.

LOUÉ, A. (1978). The interaction of potassium with other growth factors, particularly with other nutrients. Proceedings of the 11 th Congress of the International Potash Institute, 407-434.

Malavolta, E. (1980) Elementos de nutrição mineral de plantas. São Paulo/SP: Agronômica Ceres.

Malavolta, E.; Crocomo, O. J. (1982). O potássio e a planta. In: YAMADA, T.; IGUE, K.; MUZILLI, O.; USHERWOOD, N.R. Potássio na agricultura brasileira. Piracicaba: IPF/IIP, 95-162.

Marconatto, L.; Marcuzzo, L. L. Relação entre os nutrientes aplicados na cultura com a composição química e perdas durante o armazenamento de bulbos de cebola. (2020). Global Science and Technology, 13:(2), 28-35.

Marconatto, L.; Marcuzzo, L. L. Perda de massa, brotamento e podridão de bulbo durante a armazenagem de cebola. (2021). Revista Agronomia Brasileira, 5, 17.

Marconatto, L. J.; Koehler, H. S.; Marcuzzo, L. L. Incidência de doenças em cebola armazenada na Região do Alto Vale do Itajaí/SC. (2017). Summa Phytopathologica, 43:(3), 243-245.

Menezes Júnior, F. O. G. (2016). Colheita, cura, armazenamento, classificação, embalagem, padronização e comercialização. In: Menezes Júnior, F. O. G.; Marcuzzo, L. L. Manual de boas práticas agrícolas: sustentabilidade das lavouras de cebola do estado de Santa Catarina. Florianópolis: Epagri, 123135.

Menezes Júnior, F. O. G.; Gonçalves, P. A. S.; Vieira Neto, J. Produtividade da cebola em cultivo mínimo no sistema convencional e orgânico com biofertilizantes. (2014). Horticultura Brasileira, 32:(4), 475-481.

Menezes Júnior, F. O. G.; Gonçalves, P. A. S.; Vieira Neto, J. Produtividade, incidência de tripes e perdas pós-colheita da cebola sob adubação orgânica e uso de biofertilizantes.(2013). Revista de Ciências Agroveterinárias, 12:(3), 264-270.

Menezes Júnior, F. O. G.; Vieira Neto, J.; Kurtz, C. Crescimento, desenvolvimento, produtividade e perda 
pós-colheita da cebola em função de podas na fase de produção de mudas. (2013). Revista de Ciências Agroveterinárias, 12:(2),141-148.

Menezes Júnior, F. O. G.; Vieira Neto, J. Produção da cebola em função da densidade de plantas.(2012). Horticultura Brasileira, 30:(4), 733-739.

Moretti, C. L. (2007). Manual de Processamento Mínimo de Frutas e Hortaliças. Brasília: Embrapa Hortaliças.

Nylund, R. E. The response of onions to soil and foliar applications of manganese and to soil applications of other trace elements. (1952). Journal of the American Society for Horticultural Science, 60, 283-285.

Resende, G. M.; Costa, N. D. Características produtivas e conservação pós-colheita de cebola (Allium cepa L.) cv. Franciscana IPA-10 em diferentes espaçamentos de plantio, em cultivo de inverno. (2004). Horticultura Brasileira, 22:(2).

Resende, G. M.; Costa, N. D.; Alvarenga, M. A. R. Rendimento e perda de peso de bulbos de cebola cv. Texas grano $502 \mathrm{ppr}$ em diferentes espaçamentos de plantio. (2005). Caatinga, 18:(1) 28-34.

Resende, G. M.; Costa, N. D. Épocas de plantio e doses de nitrogênio e potássio na produtividade e armazenamento da cebola. (2008). Pesquisa Agropecuária Brasileira, 43:(2), 221-226.

Resende, G. M.; Costa, N. D. Épocas de plantio e doses de nitrogênio e potássio na produtividade e armazenamento da cebola. (2009). Ciência Agrotécnica, 33:(5), 1314-1320.

Souza, M.; Comi, J. J.; Jucinei, J.; Leguizamón, E. S.; Kurtz, C.; Brunetto, G.; Müller Júnior, V.; Ventura, B.; Camargo, A. P. Matéria seca de plantas de cobertura, produção de cebola e atributos químicos do solo em sistema plantio direto agroecológico. Ciência Rural, 43:(1), 21-27.

Werner, H.; Boff, P.; Gonçalves, P. A. S.; Debarba, J. F. (1996). Registro sobre deficiência de zinco em canteiros de mudas de cebola no Alto Vale do Itajaí. In: Reunião de Pesquisa da Cebola no Mercosul, Ituporanga, Epagri. 